\title{
ACUTE STROKE: FUNCTIONAL OUTCOME PREDICTORS
}

\author{
S. M. Sujatha ${ }^{1}$, A. Ramalingam², Vinodkumar Radhakrishnan ${ }^{3}$, G. Vasumathi ${ }^{4}$, K. Valarmathi ${ }^{5}$, S. Anu ${ }^{6}$ \\ ${ }_{1}^{1}$ Senior Assistant Professor, Department of General Medicine, Stanley Medical College, Chennai. \\ ${ }^{2}$ Senior Assistant Professor, Department of General Medicine, Stanley Medical College, Chennai. \\ ${ }^{3}$ Post Graduate, Department of General Medicine, Stanley Medical College, Chennai. \\ ${ }^{4}$ Associate Professor, Department of General Medicine, Stanley Medical College, Chennai. \\ ${ }^{5}$ Associate Professor, Department of Pathology, Stanley Medical College, Chennai. \\ ${ }^{6}$ Post Graduate, Department of General Medicine, Stanley Medical College, Chennai.
}

\section{ABSTRACT}

\section{BACKGROUND}

Ischemic strokes account for $>80 \%$ of total stroke events. Biochemical modalities like serum uric acid, ESR, CRP, Serum Fibrinogen will be a low cost and useful way to predict functional outcome after ischemic stroke. The Barthel ADL index it is an ordinal scale helping us to measure performances in ADL-activities in daily living. The present study aims to study the Biochemical parameters Uric Acid, CRP, ESR and Fibrinogen in Ischemic Stroke patients and to assess functional outcome in these patients using Barthel Index at admission and at discharge.

\section{MATERIALS AND METHODS}

The present study was undertaken under the Department of Internal Medicine, Govt. Stanley Hospital, Chennai, in 75 patients above 18 yrs. of age presenting with symptoms suggestive of acute stroke at medical OPD/wards/ICU, proven by imaging as ischemic stroke after proper consent were subjected to detailed history taking, complete physical examination and the relevant laboratory investigations as per proforma. Subjects were grouped under mild/moderate/severe categories as per Barthel scoring. A prospective observational study design was chosen and descriptive statistics was done for all data and suitable statistical tests of comparison were done.

\section{RESULTS}

The groups contain subjects with the same basic demographic characteristics, age and gender. The duration of stay in hospital increases with Barthel score. There is an increasing trend of diabetes mellitus and hypertension with stroke severity assessed functionally as per Barthel scores. There is an increasing trend of raised CRP, ESR levels, Uric Acid and Fibrinogen levels with stroke severity. By assessing the functional outcome using Barthel index in ischemic stroke patients at admission and discharge, the average Barthel score in patients at the time of admission was 52.27 in comparison to significantly increased Barthel score at discharge (56) with a p-value of 0.0000 according to paired t-test.

\section{CONCLUSION}

CRP, ESR, Fibrinogen, Uric Acid have also been found to be useful as early indicator of prognosis in Stroke patients. Inclusion of these tests in patients with acute stroke provides clinicians with a low cost and useful way to predict functional outcome af ter ischemic stroke as measured by Barthel index, which has been proved to have a strong correlation with inflammatory markers.

\section{KEYWORDS}

ESR, CRP, Fibrinogen, Uric Acid, Ischemic Stroke Patients, Barthel Index.

HOW TO CITE THIS ARTICLE: Sujatha SM, Ramalingam A, Radhakrishnan V, et al. Acute stroke: functional outcome predictors. J. Evolution Med. Dent. Sci. 2016;5(23): 1213-1217, DOI: 10.14260/jemds/2016/283

\section{INTRODUCTION}

Stroke is defined as an abrupt onset of a neurological deficit that is attributable to a focal vascular cause. Stroke has occurred if the neurological signs and symptoms lasts $>24$ hrs. or brain infarction is demonstrated by imaging techniques. Stroke entails a high socio-economic burden due to increased morbidity and mortality. Biochemical modalities will be a low cost and useful way to predict functional outcome after ischemic stroke. A WHO collaborative study in 12 countries showed that the incidence rates of stroke ranged from 0.2 to 2.5 per 1000 population per year.

Financial or Other, Competing Interest: None.

Submission 05-02-2016, Peer Review 02-03-2016,

Acceptance 07-03-2016, Published 18-03-2016.

Corresponding Author:

S. M. Sujatha,

No. 1, $8^{\text {th }}$ Street, Balaji Nagar,

Nanganallur, Chennai-61.

E-mail: smsuja2011@yahoo.com

DOI: $10.14260 /$ jemds $/ 2016 / 283$
Analysis of data on various studies shows that about $2 \%$ of cases in hospital, $4.5 \%$ medical patients and $20 \%$ of admissions in neurology are due to Stroke.

\section{Incidence and Prevalence of Stroke in India}

Stroke burden of a community is best reflected by the incidence. There is only one well-defined population based study from Vellore in South India by Abraham, Daniel (1972) and Sunder Rao (1973). This was conducted in two phases. In the first phase during 1968-69, total urban and rural population of 258,576 was studied.

The prevalence rate was more in Vellore town than in rural areas and the same increased with age. Subsequently, between 1969 and 71 the population was kept under surveillance and at the end of 2 years, prevalence and annual incidence rate of 84 and 13 respectively per 1,00,000 population was found. The second study was earned out as a part of WHO collaborative study in Rohtak, Haryana, between 1971 and 1974. 
The incidence was 27 per 100000 . Though various prevalence studies were already done, prevalence by definition misses those who died or recovered from stroke. As the proportion of cases that either die or recover from stroke is more than 60\%, the prevalence figures tend to underestimate the burden of disease by a fair margin. In one study, overall range was 90 to 222 per 100,000 (TIA and Death not Accounted) Ischemic stroke from thrombosis and embolism constitute between $47.3 \%$ and $82.75 \%$ of all strokes. The incidence of haemorrhagic stroke was between $13.6 \%$ and $37.9 \%$ of all stroke cases. It is found that stroke is fairly common in young Indians $<40$ years since they constitute 18.8 to $32 \%$ of all stroke cases.

\section{AIMS AND OBJECTIVES}

1. To study the Biochemical Parameters Uric Acid, CRP, ESR and Fibrinogen in Ischemic Stroke Patients.

2. To assess functional outcome in these patients using Barthel index at admission and at discharge.

\section{MATERIALS AND METHODS}

The present study was undertaken under the Department of Internal Medicine, Govt. Stanley Hospital, Chennai, to study the usefulness of biochemical parameters in predicting functional outcome in any patients above 18 yrs. of age presenting with symptoms suggestive of acute stroke at medical OPD/wards/ICU, proven by imaging as ischemic stroke.

\section{Study Universe}

All patients above 18 yrs. of age presenting with symptoms suggestive of acute stroke at medical OPD/wards/ICU, proven by imaging as ischemic stroke were included in the study.

\section{Duration}

Jan 2014 to Sep 2014.

\section{STUDY DESIGN}

\section{Prospective Observational Study \\ Sample Size - 75}

Sample size was determined on the basis of a pilot study in which the prevalence of serum fibrinogen levels was measured at $25 \%$. We calculated a minimum sample size of 72 patients was required in each group, assuming a type 1 error (Two-tailed) of 0.05 and a margin of error of $10 \%$. Therefore, the final sample selected was $n=75$.

\section{Data Collection}

All the patients who fulfilled the inclusion criteria above 18 years of age and subjected to detailed history taking, complete physical examination and the relevant laboratory investigations as per proforma, exclusively designed for the study. Prior permission from Institutional Ethics Committee was taken, written/informed consent from every subject was taken. Patients were classified as having mild/moderate/severe according to Barthel index and the biochemical parameters were compared in each group.

\section{Statistics}

Descriptive statistics was done for all data and statistical tests of comparison were done. Continuous variables were analysed with the Unpaired ' $t$ ' test/ANOVA and categorical variables were analysed with the Chi-Square Test and Fisher Exact Test. Statistical significance was taken as $\mathrm{P}<0.05$.
The data was analysed using Epi Info software (7.1.0.6 version; Center for disease control, USA) and Microsoft Excel 2010.

\section{Stroke Definition}

"Rapidly developing clinical signs of focal (or global) disturbance of cerebral function with symptoms lasting 24 hours or longer or leading to death with no apparent cause other than of vascular origin." Stroke manifests by various neurological signs and symptoms depending on extent, area of involvement and the underlying causes. These include coma, hemiplegia, paraplegia, monoplegia, cranial nerve palsy, speech disturbance and sensory impairment, etc. Of these, hemiplegia is the most common presentation seen in about $90 \%$ of patients.

\section{Barthel ADL Index}

Is an ordinal scale helping us to measure performances in ADL- activities in daily living. Every performance item is given a rating using this scale with a score for every level exhibited by the patient. There are 10 different factors depicting ADL and mobility. Larger number will have an association with a higher probability of the patient being able to live independently at home after getting discharged from hospital 69.

\begin{tabular}{|c|c|}
\hline \multicolumn{2}{|c|}{ Bladder } \\
\hline Bathing & Toilet use \\
\hline Grooming & Transfers (Bed/Chair) \\
\hline Dressing & Mobility (Levels) \\
\hline Bowels & Stairs \\
\hline
\end{tabular}

\section{Usage}

Helps in determining a basal functional level of the patient and useful in monitoring any improvement in ADLs over time. Scoring is done on the basis of whether they receive help for doing the task varies between $0,5,10,15$. Summation of scores of each of the items is done to get a final score. Greater the total score means more "Independent" the patient is. A patient is independent when he does not need any assistance for any portion of the task. When he/she is able to do $50 \%$ of task independently "Middle" score is given. Functional status was measured with Barthel Index of ADL. Accordingly, they were divided into 3 groups.

\begin{tabular}{|c|c|}
\hline Score & Disability \\
\hline$<41$ & Severely \\
\hline $4-60$ & Moderately \\
\hline$>60$ & Mildly \\
\hline
\end{tabular}

\section{Exclusion Criteria}

1. Haemorrhagic stroke patients.

2. Patients with any source of sepsis/infectious disease prior 4 weeks.

3. Patients presenting after 72 hours of onset.

4. Patients having evidence of renal disease, active hepatic disease, history of prior MI/ischemic heart disease or surgery within preceding 3 months.

5. Patient with any form of arthritis.

6. Recent trauma/burns.

7. Patients with prior history of stroke or TIA's.

8. Patients on any lipid lowering agents.

9. Patients with venous stroke and stroke due to tumours. 


\section{RESULTS}

\section{Age Distribution and Gender}

Age and gender was found statistically not significant. It means that there is no difference between the groups. In other words, the groups contain subjects with the same basic demographic characteristics.

\section{Duration of Stay in Hospital}

By assessing the functional outcome using Barthel index in ischemic stroke patients, in mild patients' category the average duration of stay in hospital was reduced significantly to 7.30 days in comparison to 8.71 days in moderate patient category and 9.61 days in severe patient category with a p-value of 0.000365 according to ANOVA test. We conclude if the patient is classified under mild category using Barthel index decreases is the duration of stay in hospital.

\section{CRP Levels}

By assessing the functional outcome using Barthel index in ischemic stroke patients, in mild patients' category the CRP levels was reduced significantly to $8.61 \mathrm{mg} / \mathrm{dL}$ in comparison to $12.75 \mathrm{mg} / \mathrm{dL}$ in moderate patient category and $18.05 \mathrm{mg} / \mathrm{dL}$ in severe patient category with a pvalue of 0.000 according to ANOVA test. We conclude that there is real advantage if the patient is classified under mild category using Barthel index, which is associated with decreased CRP levels. ${ }^{(1)}$

\section{ESR Levels}

By assessing the functional outcome using Barthel index in ischemic stroke patients, in mild patients' category the ESR levels was reduced significantly to $9.59 \mathrm{~mm}-\mathrm{hr}$. in comparison to $18.71 \mathrm{~mm}$-hr. in moderate patient category and $19.65 \mathrm{~mm}$-hr. in severe patient category with a pvalue of 0.000 according to ANOVA test. We conclude that there is real advantage if the patient is classified under mild category using Barthel index, which in turn is associated with decreased ESR levels.

\section{Uric Acid Levels}

By assessing the functional outcome using Barthel index in ischemic stroke patients, in mild patients' category the uric acid levels were reduced significantly to $6.74 \mathrm{mg} / \mathrm{dL}$ in comparison to $9.00 \mathrm{mg} / \mathrm{dL}$ in moderate patient category and $11.10 \mathrm{mg} / \mathrm{dL}$ in severe patient category with a p-value of 0.000 according to ANOVA test. We conclude that there is real advantage if the patient is classified under mild category using Barthel index, which in turn is associated with decreased uric acid levels.

\section{Serum Fibrinogen Level}

By assessing the functional outcome using Barthel index in ischemic stroke patients, in mild category patients the fibrinogen levels were reduced significantly to 325.70 $\mathrm{mg} / \mathrm{dL}$ in comparison to $414.29 \mathrm{mg} / \mathrm{dL}$ in moderate patient category and $461.52 \mathrm{mg} / \mathrm{dL}$ in severe patient category with a p-value of 0.000118 according to ANOVA test. We conclude that there is real advantage if the patient is classified under mild category using Barthel index, which in turn is associated with decreased serum fibrinogen levels.

\section{Admission/Discharge/Death}

In our study, 66 patients got discharged and 9 patients expired. Mortality rate $12 \%$. By conventional criteria, the association between the study groups and Barthel scores (Admission and Discharge) is considered to be statistically significant since $p<0.05$. This indicates that there is a true difference among the study groups and the difference is significant. In simple terms, by assessing the functional outcome using Barthel index in ischemic stroke patients at admission and discharge, the average Barthel score in patients at the time of admission was 52.27 in comparison to significantly increased Barthel score at discharge (56) with a p-value of 0.0000 according to paired t-test. We conclude that there is real advantage if the patient is classified using Barthel index for diagnosis and prognosis, which in turn is associated with stroke severity.

\section{DISCUSSION}

Uric acid is an antioxidant increased in ischemia conferring protection against free radical injury. CRP and ESR are the earliest acute phase reactants to increase during the inflammatory response and independent predictors of short term stroke outcome. Atherosclerosis is an inflammatory process and effect of CRP is self-explained. CRP is associated with metabolic syndrome and onset of DM. Evidence does show us that C-reactive protein independently identifies cerebral thrombotic episodes.(2)

ESR is an easy and affordable blood test for monitoring inflammatory response and it also helped in prediction of outcome of stroke patients in the shorter duration.(3) Erythrocyte sedimentation rate $>28$ millimetre/hour reflects a worse prognosis.(4) The relationship between erythrocyte sedimentation rate and the outcome in stroke patients can also represent the alterations in the usual level of natural occurring anticoagulants.

Higher levels of fibrinogen levels have a strong correlation with the atherosclerotic complications namely MI and cerebrovascular events. Thrombosis is found to play a significant role in both and fibrinogen has an important role to play in thrombosis. (5)

Fibrinogen has a direct relationship in ischemic stroke and its increasing levels is associated with marked reduction in cerebral blood flow. Inclusion of these tests in patients with acute stroke provides a low cost and useful way to predict functional outcome after ischemic stroke, which in turn is measured by Barthel index.

\section{CONCLUSION}

CRP apart from being an inflammatory marker has also been found to be a highly sensitive, non-specific and an independent risk factor for prediction of ischemic stroke.(6) Similarly ESR, fibrinogen, uric acid have also been found to be useful as early indicator of prognosis in stroke patients.(7)

The present study is done without any haste involving the above four parameters to predict the outcome among stroke patients. This study correlates with the previous studies done by eminent people as quoted by my citations. $(8,9)$ Inclusion of these tests in patients with acute stroke provides clinicians with a low cost and useful way to predict functional outcome after ischemic stroke as measured by Barthel index, which has been proved to have a strong correlation with inflammatory markers. 


\begin{tabular}{|c|c|c|c|c|c|c|c|}
\hline Age Groups & All & $\mathbf{\%}$ & Mild & $\mathbf{\%}$ & Moderate & \% & Severe \\
\hline 26 to 35 & 1 & 1.33 & 1 & 3.70 & 0 & 0.00 & 0 \\
\hline 36 to 45 & 10 & 13.33 & 3 & 11.11 & 3 & 17.65 & 4 \\
\hline 46 to 55 & 28 & 37.33 & 16 & 59.26 & 5 & 29.41 & 7 \\
\hline 56 to 65 & 17 & 22.67 & 3 & 11.11 & 4 & 23.53 & 10 \\
\hline 66 to 75 & 12 & 16.00 & 3 & 11.11 & 4 & 23.53 & 5 \\
\hline 75 to 85 & 7 & 9.33 & 1 & 3.70 & 1 & 5.88 & 5 \\
\hline Total & $\mathbf{7 5}$ & $\mathbf{1 0 0}$ & $\mathbf{2 7}$ & $\mathbf{1 0 0}$ & $\mathbf{1 7}$ & $\mathbf{1 0 0}$ & $\mathbf{3 1}$ \\
\hline \multicolumn{7}{|c|}{} \\
\hline
\end{tabular}

\begin{tabular}{|c|c|c|c|c|c|c|c|c|}
\hline Gender & All & $\mathbf{\%}$ & Mild & $\mathbf{\%}$ & Moderate & $\mathbf{\%}$ & Severe & $\mathbf{\%}$ \\
\hline Male & 41 & 54.67 & 18 & 66.67 & 7 & 41.18 & 16 & 51.61 \\
\hline Female & 34 & 45.33 & 9 & 33.33 & 10 & 58.82 & 15 & 48.39 \\
\hline Total & $\mathbf{7 5}$ & $\mathbf{1 0 0}$ & $\mathbf{2 7}$ & $\mathbf{1 0 0}$ & $\mathbf{1 7}$ & $\mathbf{1 0 0}$ & $\mathbf{3 1}$ & $\mathbf{1 0 0}$ \\
\hline \multicolumn{8}{|c|}{ Chi-square } \\
\hline \\
\hline
\end{tabular}

\begin{tabular}{|c|c|c|c|c|c|c|c|c|}
\hline Duration of Stay in Days & All & $\mathbf{\%}$ & Mild & $\mathbf{\%}$ & Moderate & $\mathbf{\%}$ & Severe & \% \\
\hline$\leq 6$ & 15 & 20.00 & 10 & 37.04 & 2 & 11.76 & 3 & 9.68 \\
\hline 7 to 8 & 28 & 37.33 & 13 & 48.15 & 6 & 35.29 & 9 & 29.03 \\
\hline 9 to 10 & 17 & 22.67 & 2 & 7.41 & 7 & 41.18 & 8 & 25.81 \\
\hline 11 to 12 & 10 & 13.33 & 2 & 7.41 & 2 & 11.76 & 6 & 19.35 \\
\hline 13 to 14 & 5 & 6.67 & 0 & 0.00 & 0 & 0.00 & 5 & 16.13 \\
\hline Total & $\mathbf{7 5}$ & $\mathbf{1 0 0}$ & $\mathbf{2 7}$ & $\mathbf{1 0 0}$ & $\mathbf{1 7}$ & $\mathbf{1 0 0}$ & $\mathbf{3 1}$ & $\mathbf{1 0 0}$ \\
\hline \multicolumn{8}{|c|}{} \\
\hline
\end{tabular}

\begin{tabular}{|c|c|c|c|}
\hline Complications & Mild & Moderate & Severe \\
\hline Hemiparesis/plegia & 25 & 16 & 31 \\
\hline Aphasia/Dysphasia & 9 & 10 & 17 \\
\hline CN involvement & 23 & 16 & 18 \\
\hline Altered Sensorium & 0 & 1 & 14 \\
\hline Headache & 4 & 2 & 4 \\
\hline Vomiting & 1 & 3 & 3 \\
\hline Seizures & 1 & 0 & \\
\hline
\end{tabular}

\begin{tabular}{|c|c|c|c|c|c|c|c|c|}
\hline CRP Levels & All & $\mathbf{\%}$ & Mild & $\mathbf{\%}$ & Moderate & $\mathbf{\%}$ & Severe & \% \\
\hline$\leq 6$ & 18 & 24.00 & 11 & 40.74 & 3 & 17.65 & 4 & 12.90 \\
\hline$>6$ & 57 & 76.00 & 16 & 59.26 & 14 & 82.35 & 27 & 87.10 \\
\hline Total & $\mathbf{7 5}$ & $\mathbf{1 0 0}$ & $\mathbf{2 7}$ & $\mathbf{1 0 0}$ & $\mathbf{1 7}$ & $\mathbf{1 0 0}$ & $\mathbf{3 1}$ & $\mathbf{1 0 0}$ \\
\hline \multicolumn{7}{|c|}{ Table 5: CRP Levels as per Barthel Index } \\
\hline
\end{tabular}

\begin{tabular}{|c|c|c|c|c|c|c|c|c|}
\hline $\begin{array}{c}\text { ESR } \\
\text { (mm-hr.) }\end{array}$ & All & \% & Mild & \% & Moderate & \% & Severe & \% \\
\hline$\leq 10$ & 33 & 44.00 & 19 & 70.37 & 5 & 29.41 & 9 & 29.03 \\
\hline 11 to 20 & 19 & 25.33 & 8 & 29.63 & 4 & 23.53 & 7 & 22.58 \\
\hline 21 to 30 & 19 & 25.33 & 0 & 0.00 & 6 & 35.29 & 13 & 41.94 \\
\hline 31 to 40 & 4 & 5.33 & 0 & 0.00 & 2 & 11.76 & 2 & 6.45 \\
\hline Total & $\mathbf{7 5}$ & $\mathbf{1 0 0}$ & $\mathbf{2 7}$ & $\mathbf{1 0 0}$ & $\mathbf{1 7}$ & $\mathbf{1 0 0}$ & $\mathbf{3 1}$ & $\mathbf{1 0 0}$ \\
\hline \multicolumn{8}{|c|}{} \\
\hline
\end{tabular}

\begin{tabular}{|c|c|c|c|c|c|c|c|c|}
\hline Uric Acid (mg/dL) & All & $\mathbf{\%}$ & Mild & $\mathbf{\%}$ & Moderate & $\mathbf{\%}$ & Severe & \% \\
\hline$\leq 7$ & 27 & 36.00 & 19 & 70.37 & 6 & 35.29 & 2 & 6.45 \\
\hline$>7$ & 48 & 64.00 & 8 & 29.63 & 11 & 64.71 & 29 & 93.55 \\
\hline Total & $\mathbf{7 5}$ & $\mathbf{1 0 0}$ & $\mathbf{2 7}$ & $\mathbf{1 0 0}$ & $\mathbf{1 7}$ & $\mathbf{1 0 0}$ & $\mathbf{3 1}$ & $\mathbf{1 0 0}$ \\
\hline \multicolumn{8}{|c|}{ Table 7: Uric Acid Levels as per Barthel Index } \\
\hline
\end{tabular}




\begin{tabular}{|c|c|c|c|c|c|c|c|c|}
\hline $\begin{array}{c}\text { Fibrinogen } \\
\text { (mg/dL) }\end{array}$ & All & $\mathbf{\%}$ & Mild & $\mathbf{\%}$ & Moderate & $\mathbf{\%}$ & Severe & \% \\
\hline$\leq 400$ & 44 & 58.67 & 23 & 85.19 & 9 & 52.94 & 12 & 38.71 \\
\hline$>400$ & 31 & 41.33 & 4 & 14.81 & 8 & 47.06 & 19 & 61.29 \\
\hline Total & $\mathbf{7 5}$ & $\mathbf{1 0 0}$ & $\mathbf{2 7}$ & $\mathbf{1 0 0}$ & $\mathbf{1 7}$ & $\mathbf{1 0 0}$ & $\mathbf{3 1}$ & $\mathbf{1 0 0}$ \\
\hline \multicolumn{7}{|c|}{ Table 8: Fibrinogen Levels as per Barthel Index } \\
\hline
\end{tabular}

\begin{tabular}{|c|c|c|c|c|}
\hline Barthel Score & Admission & $\%$ & Discharge & $\%$ \\
\hline Death & 0 & 0 & 9 & 12.00 \\
\hline Mild & 27 & 36 & 34 & 45.33 \\
\hline Moderate & 17 & 22.66 & 15 & 20.00 \\
\hline Severe & 31 & 41.33 & 17 & 22.67 \\
\hline Total & 75 & 100 & 75 & 100 \\
\hline \multicolumn{3}{|l|}{ P value Paired $t$ test } & \multicolumn{2}{|c|}{0.0000} \\
\hline \multicolumn{5}{|c|}{ Table 9: Admission and Discharge } \\
\hline
\end{tabular}

\section{REFERENCES}

1. Loewen SC, Anderson BA. "Predictors of stroke outcome using objective measurement scales." Stroke 1990;21:7881.

2. Allen CMC. Clinical diagnosis of acute stroke syndrome. QJM 1983;208:515-523.

3. Martinez J. In: Hoffman R, Benz EJ, Shattil SJ, et al. editors. Hematology, basic principles and practice. New York: Churchill Livingstone. 2nd Edn:p 1703-1713.

4. Herderschee D. Influence of transient ischemic attack or small stroke on cessation of smoking. Neuroepidemiology 1992;11:31-33.

5. Diminno G, Mancini M. Measuring plasma fibrinogen to predict stroke and myocardial infarction. Arteriosclerosis 1990;10:1-7.
6. Toole JF, Xuson CP, Janeway R, et al. Transient ischemic attack: the study of 225 patients. Neurology 1978;28(8):746-53.

7. Lehto $\mathrm{S}$, Niscanen L, Ronnemaa $\mathrm{T}$, et al. Serum uric acid is a strong predictor of stroke in patients with non-insulin dependent diabetes mellitus. Stroke 1998;29:635-9.

8. Gresham GE, Phillips TF, Labi ML. "ADL status in stroke: relative merits of three standard indexes." Arch Phys Med Rehabil 1980;61:355-358.

9. Collin C, Wade DT, Davies S, et al. "The barthel ADL index: a reliability study." Int Disability Study 1988;10:61-63. 